\title{
What's new about symptomatic reflux disease
}

\begin{abstract}
During the last 4 decades reflux disease (GERD) has evolved from being a rare clinical problem to a disease with high incidence. This automatically rises its social costs. First descriptions came from western countries only but nowadays there are many published papers from Asia and Middle East that can be found on the Internet. There is no clear explanation for this fact. Our understanding of GERD has changed over the time. At first GERD, hiatal hernia and oesophagitis were synonyms. Since the 1940s when the first manometrical studies were done it was concerned as lower oesophageal sphincter or peristaltic disfunction. The following years gave a definition of acid-peptic disorder. Nowadays all this concepts are mixed together and we are considering GERD as a heterogeneous clinical problem. In this paper we would like to present up-to-date knowledge about GERD.
\end{abstract}

Keywords: gastroesophageal reflux disease, hiatal hernia, oesophagitis.

DOI: $10.1515 /$ pjph-2015-0015

\section{INTRODUCTION}

During the last 4 decades, the reflux disease (GERD) has evolved from being a rare clinical problem to a disease with high incidence. This automatically led to its increased social impact. Earliest accounts were made in countries of the so-called West, but nowadays one can find lots of papers on reflux published by Asian and Middle Eastern researchers. No clear explanation could be provided for this fact. Also, the way we understand GERD has changed over time. Initially, the words: GERD, hiatal hernia and oesophagitis were used synonymously. Since the 1940s, when first manometrical studies were performed, researchers started referring to it as either lower oesophageal sphincter or peristaltic disfunction. Later, a definition of an acid-peptic disorder appeared. Nowadays, all these concepts are used together and GERD is understood as a heterogeneous clinical problem. Each new use of the concept of GERD was strictly matched with new developments in the diagnosis. Barium swallow test shows hiatal hernia and recurrent move of gastric contents to the oesophagus. Since the moment it appeared, manometry has been showing the dynamic function of the lower oesophageal sphincter during the swallowing process. The severity was then clearly described with the use of endoscopy in patients with erosive GERD. In spite of that, there was a large group of patients with no mucosal injuries, yet, with typical symtoms of GERD. It was $\mathrm{pH}$-studies that finally helped them. Since the 2000s, it is possible to do combined impedance and $\mathrm{pH}$-metry studies which significantly changed the definition and understanding of GERD. Also, we should not forget about the key concept of the 1990s pharmacotherapy, namely proton pump inhibitors. Their widespread use and effectiveness in clinical contexts almost redefined GERD as either a positive or negative response to therapy [1]. Hence, there is no space for any simplifications in defining GERD.

During the last twenty years, we have been successfully diagnosing over 200 patients annually who were referred to as suffering from GERD. Our facility is one of the first research centers in Poland to deal with oesophageal manometry and pH-metry. Also, it was one of the first centers to do combined impedance and $\mathrm{pH}$-studies (MII-pH). Not to mention the fact that it was the first place in Eastern Europe to be equipped with high resolution manometry and impedance (HRMI) device set to perform oesophageal function tests. Two authors of this article are HRMI and MII-pH studies certified trainers. Each year, we perform over 90 fundoplications (mostly laparoscopic Nissen fundoplications). We also have some experience in Stretta procedure in GERD.

\section{Definition of GERD}

As it was mentioned before, the definition of GERD has changed over the last 40-50 years. Along that, there was an introduction of PPI's and new techniques of diagnosing both motility disorders and GERD. It changed the clinicians' point of view. Before that, antacids and histamine 2 blockers had had a limited treatment value over the time. From the 1990's on, together with PPI's, it has become commonplace to control GERD-related complications (except Barrett's oesophagus) using these method. Some time passed and it became clear that symptoms still last in some group of patients. The first good and clear definition was done by Jamieson 
and Duranceau. According to their definition, there is both a physiological and a pathological reflux (referred to as the reflux disease) with or without morphological changes in oesophageal mucosa. A group of experts decided to divide GERD into subcategories back in 2002, during the Oporto conference. Due to their decision, the classification changed as follows. Acid reflux should be used to describe refluxed gastric juice with a $\mathrm{pH}$ less than 4 which can either reduce the $\mathrm{pH}$ of the esophagus to below 4 or occur when esophageal $\mathrm{pH}$ is already below 4. Superimposed acid reflux is an acidic reflux episode that occurs before esophageal $\mathrm{pH}$ has recovered to above 4 . Weakly acidic reflux describes reflux events that result in an esophageal pH between 4 and 7 . Weakly alkaline reflux should be reserved for reflux episodes during which nadir esophageal $\mathrm{pH}$ does not drop below 7 [2]. The developments in diagnosing and treatment prompted the international consensus conference resulting in "Montreal definition" of GERD: " "a chronic condition in which gastric content is regurgitated into the oesophagus and causes bothersome symptoms and/or complications" [3].

\section{Epidemiology}

Analysis of 28 studies from different countries shows that the prevalence of GERD is increasing (GERD was defined by typical symptoms or by the Montreal definition). Its estimated values are: $18.1-27-8 \%$ in North America, 8.5-25.9\% in Europe, 2.5-7.8\% in East Asia, 8.7-33.1\% in the Middle East, 11.6 in Australia and 23\% in South Africa. This data were compared to those done before 1995 . The data showed that there is a $50 \%$ higher prevalence in the US, Europe and East Asia [4].

GERD is associated with some disorders like reflux symptoms, erosive oesophagitis, Barrett's oesophagus, oesophageal adenocarcinoma. These disorders are related to sex, race and place of living. Reflux symptoms are the same in men and women. Men make $60 \%$ of patients with erosive lesions, $70 \%$ of patients with Barrett's oesophagus and $80 \%$ of patients with oesophageal adenocarcinoma. Also, there are racial differences concerning the prevalence of the disease. Symptoms are almost the same in both groups, yet white people are more affected with erosive GERD (60\%), Barrett's oesophagus (70\%), and the prevalence for adenocarcinoma, which is 5 times higher [5].

Another issue that should raise concerns is the rising number of obese patients. Singh et al. have done a meta-analysis showing the correlation between the waist circumference and waist-to-hip-ratio correlate more strongly than BMI with erosive lesions (OR 1.87, 95\%CI 1.51 to 2.31 ), Barrett's oesophagus (OR 1.98, 95\% CI 1.52 to 2.57 ) and oesophageal adenocarcinoma (OR 2.51, 95\% CI 1.54 to 4.06) compared to normal individuals [6].

\section{Management of GERD}

A rising number of patients suffering from GERD and lack of any effective pharmacological control led to the development of surgical methods for treatment, between the 1950s and the 1970s. Lack of control was combined with poor understanding of the pathogenesis of this disease. It was achieved in the late 1980's with PPI's. In some countries, this led to a decrease in the number of studies on another treatment options. Within the next years, it has become clear that reflux still exists in PPI's therapy. Kharilas et al. have provided an overview of PPI's efficacy for treating various GERD syndromes. Its efficacy diminishes from oesophagitis through heartburn, regurgitation, chest pain, chronic cough to asthma. The data showed that weakly-acid or non-acid reflux can also cause symptoms like heartburn [7].

Lifestyle change is one of the general recommendations. The efficacy of this method in curing GERD is anecdotal. This concept consists of recommending a healthy diet and avoiding some food products or activities that can be associated with symptoms. The recommendations depend on the patient's individual needs which requires personalized advice. Obese patients are another group that requires a specific approach. There is huge body of evidence that gastric banding decreases the number of existing reflux symptoms, but at the same time, it can lead up to $23 \%$ to de novo reflux symptoms and to de novo oesophagitis [8].

Pathogenesis of GERD is multifactorial, but the level of acid secretion is the same as in normal individuals [9]. Nevertheless, all the patients with GERD symptoms are treated with PPIs. These are widely recommended in all national guidelines all over the world. There are only minute differences between them, so choosing either of them should make no difference to the patient. Most patients are treated with a single dose of PPI. Double dose once a day could be more effective in some cases, though. In case there is no good clinical outcome, the dose can be increased to twice a day. Nocturnal acid secretion can be stopped with $\mathrm{H} 2$ blocker, but after a few days there is no more effectiveness of this drugs [10-12].

As it was mentioned before, medical treatment is not always effective. The failure should be the trigger for reconsidering the diagnosis. There are no specific symptoms for GERD. The best way of reflux testing is combined intraluminal $\mathrm{pH}$-impedance. It can be performed also in patients undergoing therapy $[13,14]$. Analysis of $\mathrm{pH}$ monitoring (MII-pH) can lead to 4 different phenotypes in patients. Phenotype 1 (symptomatic GERD) patient has excessive reflux and positive symptom association to reflux and should be treated with high doses of PPIs or with antireflux surgery. Phenotype 2 (symptomatic GERD) patient has physiological reflux with positive symptom association, it is so called hypersensitive oesophagus. The treatment with conventional therapy is likely to fail. Phenotype 3 (GERD, symptoms not directly related) patient has excessive reflux with negative symptom association. Antireflux therapy is very rarely effective. There are no clear guidelines what to do. Phenotype 4 (no GERD) patient has physiological reflux and negative symptom association [13].

\section{Surgery and endoscopy in GERD}

The indications for surgical treatment of well-documented GERD are:

1. Patient did not improve in spite of intensive pharmacological therapy;

2. Patient chooses surgical treatment despite adequate pharmacological treatment, are young, have to constantly adhere to medical therapy even for the rest of their lives, which involves high expenses, or whose lifestyle excludes regular treatment; 
3. Patient develop reflux disease complications (Barrett's oesophagus, high grade oesophagitis);

4. Patient has accompanying large hiatal hernia with complications such as bleeding or dysphagia;

5. Patient has atypical symptoms (asthma, hoarse, chest pain, choking).

Nissen fundoplication is a gold standard for surgical treatment of GERD. The goal of the surgical anti-reflux procedure is to stop gastric content regurgitation. During the 5 years of randomized clinical trial, there was no significant overall difference in symptomatic remission rate compared to PPIs therapy but persistent regurgitation was more often in this group. [13]

During the last 20 years, several endoscopic antireflux procedures were developed. The first one was called EndoCinch - endoscopic suturing technique, second was Stretta - device that delivers radiofrequency energy to oesophago-gastric junction. The last one is EsophyX - endoscopic placation device. The first 2 methods are not recommended because of lack of effect in sham-controlled trials. The EsophyX is still during clinical trials [15-18].

The new methods are: LINX system and electrostymulation of LES. The LINX system is a magnetic banding of the LES and it was shown to reduce acid exposure from $10.9 \%$ to $3.3 \%$, reduce PPI usage and improve other symptoms. The follow-up was done after 1 year, there was no control group [19]. The second one is a laparoscopical implantation of electrodes and stimulation of LES. It is expected to increase LES pressure. 24 patient without significant hiatal hernia were treated with this method. There was no sham group [20].

\section{CONCLUSIONS}

The increasing number of patients with GERD and its complications, together with increasing obesity levels reported in population all across the world, is worrying sign for physicians. The most interesting thing from the last years, is the correlation between central obesity and BMI and reflux disease. It should be remembered that GERD is not a simple, one-factor disease but its pathophysiology is complicated. The point of view on GERD has changed during last 20 years but we are still in search for better methods of treatment in the future.

\section{REFERENCES}

1. Numans ME, Lau J, de Wit NJ, et al. Short-term treatment with proton-pump inhibitors as a test for gastroesophageal reflux disease: a meta-analysis of diagnostic test characteristics. Ann Intern Med. 2004;140:518-27.

2. Sifrim D, Castell D, Dent J, et al. Gastro-oesophageal reflux monitoring: review and consensus report on detection and definitions of acid, nonacid, and gas reflux. Gut. 2004;53:1024-31.

3. Vakil N, van Zanten SV, Kahrilas P, et al. Global Consensus Group. The Montreal definition and classification of gastroesophageal reflux disease: a global evidence-based consensus. Am J Gastroenterol 2006;101:1900-20.

4. El-Serag HB, Sweet S, Winchester CC, et al. Update on the epidemiology of gastro-esophageal reflux disease: a systematic review. Gut. 2014;63: 871-80.

5. Cook MB, Chow WH, Devesa SS. Oesophageal cancer incidence in the United States by race, sex, and histologic type, 1977-2005. Br J Cancer. 2009;101:855-9.

6. Singh S, Sharma AN, Murad MH, et al. Central adiposity is associated with increased risk of esophageal inflammation, metaplasia, and adenocarcinoma: a systematic review and meta-analysis. Clin Gastroenterol Hepatol. 2013;11:1399-412.e7

7. Kahrilas PJ, Boeckxstaens G. Failure of reflux inhibitors in clinical trials: bad drugs or wrong patients? Gut. 2012;61:1501-9.

8. de Jong JR, Besselink MG, van Ramshorst B, et al. Effects of adjustable gastric banding on gastroesophageal reflux and esophageal motility: a systematic review. Obes Rev. 2010;11:297-305.

9. Hirschowitz BI. A critical analysis, with appropriate controls, of gastric acid and pepsin secretion in clinical esophagitis. Gastroenterol. 1991;101:1149-58.

10. Bardhan KD, Muller-Lissner S, Bigard MA, et al. Symptomatic gastrooesophageal reflux disease: double blind controlled study of intermittent treatment with omeprazole or ranitidine. The European Study Group. BMJ. 1999;318:502-7.

11. Miner P Jr, Katz PO, Chen Y, et al. Gastric acid control with esomeprazole, lansoprazole, omeprazole, pantoprazole, and rabeprazole: a fiveway crossover study. Am J Gastroenterol 2003;98:2616-20.

12. Fackler WK, Ours TM, Vaezi MF, et al. Long-term effect of H2RA therapy on nocturnal gastric acid breakthrough. Gastroenterol. 2002;122:62532.

13. Wallner G, Solecki M, Tarnowski W, et al. Gastroesophageal reflux disease - clinical practice guidelines. Videosurgery. 2009;4(Suppl. 1):S16S24.

14. Masiak W, Wallner G, Wallner J, et al. Combined esophageal multichannel intraluminal impedance and $\mathrm{pH}$ monitoring $(\mathrm{MII}-\mathrm{pH})$ in the diagnostics and treatment of gastroesophageal reflux disease and its complications. Pol Prz Chir. 2011;83(9):488-96.

15. Wallner G, Skoczylas T, Zinkiewicz K, et al. Own experience in the treatment of gastro-esophageal junction inability. Now Lek. 2007;76 (Suppl. 1):73.

16. Schwartz MP, Wellink H, Gooszen HG, et al. Endoscopic gastroplication for the treatment of gastro-oesophageal reflux disease: a randomised, sham-controlled trial. Gut. 2007;56:20-8.

17. Arts J, Bisschops R, Blondeau K, et al. A double-blind sham-controlled study of the effect of radiofrequency energy on symptoms and distensibility of the gastro-esophageal junction in GERD. Am J Gastroenterol. 2012;107:222-30.

18. Cadière GB, Van Sante N, Graves JE, et al. Two-year results of a feasibility study on antireflux transoral incisionless fundoplication using EsophyX. Surg Endosc. 2009;23:957-64.

19. Ganz RA, Peters JH, Horgan S, et al. Esophageal sphincter device for gastroesophageal reflux disease. N Engl J Med. 2013;368:719-27.

20. Rodríguez L, Rodriguez P, Gómez B, et al. Long-term results of electrical stimulation of the lower esophageal sphincter for the treatment of gastroesophageal reflux disease. Endoscopy. 2013;45(8):595-604.

\section{Corresponding author}

Michał Solecki

16 Staszica Str., 20-081 Lublin

Tel. +48815328810

E-mail: michal.solecki77@gmail.com 